\title{
Atık Mantar Kompostunun Geleneksel ve Yeni Kullanım Alanları
}

\author{
Serap KÖKCÜ (D) 1 , Nermin SARIGÜL (iD) 2* \\ ${ }^{1}$ Burdur Mehmet Akif Ersoy Üniversitesi, Fen Bilimleri Enstitüsü, Burdur \\ ${ }^{2}$ Burdur Mehmet Akif Ersoy Üniversitesi, Fen Edebiyat Fakültesi, Burdur \\ Geliş Tarihi (Received): 17.12.2020, Kabul Tarihi (Accepted): 04.03.2021 \\ $\square$ Sorumlu Yazar (Corresponding author*): sarigul@mehmetakif.edu.tr \\ (C) +902482133051 兘 +902482133099
}

öz

Şapkalı mantar yetiştiriciliği yiyecek olarak tercih edilen bir ürün olması nedeni ile her geçen gün artmaktadır. Mantar yetiştiriciliği gıda üretiminin yanında lignoselülozik atık maddelerin biyoteknolojik geri dönüşümünün yapıldığı proseslerden biridir. Kompost içeriği mantar kültürü yapılırken değişmektedir. Lignoselülozik bileşiklerin parçalanması ve antimikrobiyal aktivitenin sağlanması için hücre dışına mantar tarafından enzimler ve kompleks bileşikler salgılanmaktadır. Çeşitli mantar kültürü çalışmaları sonucunda dünya genelinde çok fazla miktarda atık mantar kompostu açığa çıkmaktadır. Bu tür atıkların yakılarak bertaraf edilmesi çevresel açıdan ciddi sorunlara neden olmaktadır. Hasat sonrası kalan atık kompost farklı şekillerde kullanılarak değerli ürünlere dönüştürülebilir. Atık mantar kompostunun en yaygın ve geleneksel kullanım alanları; hayvan besleme, ilave katkı maddeleri ile fermentasyonu, biyogaz üretimi esnasında gübreye katılması, gübre ve toprağın iyileştirilmesidir. Son yıllarda atık mantar kompostunun değerli ürünlere çevrilmesi konusunda çalışmalar artmıştır. Yaptığımız derlemede atık mantar kompostunun geleneksel kullanım alanları yanında enzim ve antimikrobiyal madde kaynağı olarak değerlendirilmesine odaklanılmıştır.

Anahtar Kelimeler: Antimikrobiyal bileşikler, atık mantar kompostu, enzim, kullanım alanları

\section{Traditional and Alternative Use of Mushroom Compost Waste}

\begin{abstract}
The production and culture of mushrooms is increasing as a desirable addition to the cuisine since ancient times. Mushroom culture is a biotechnological process that recycles ligninocellulosic wastes, since mushrooms are food for human consumption. Mushroom compost changes during cultivation as a result of fungal activity. Extracellular enzymes and complex compounds are secreted for degradation of ligninocellulosic substrates and antimicrobial activity. A large amount of compost waste is produced worldwide in various mushroom cultivation. The disposal and burning of agricultural wastes have created major global environmental problems. This post-harvest compost waste can be used in different ways for produce value-added products. The most common and traditional uses of this waste material is in animal feeding, fermentation with other additives, mixed with other manure to produce biogas, bottom fertilizer and soil improvement. Recently efforts on conversion of mushroom compost waste into valuable products have increased. This review has focused on the use of mushroom compost waste in traditional methods and as a source for production of extracellular enzymes and antimicrobial compounds.
\end{abstract}

Keywords: Antimicrobial compounds, mushroom compost waste, enzyme, utilization

\section{GíRiş}

Dünyada var olduğu düşünülen 1,5 milyon mantar türünün, makro mantar olarak kabul edilebilen, yeterli büyüklük ve yapıda olan, şapka yapısı oluşturabilen 140.000 türü bulunduğundan söz edilmektedir. Bu türlerin belirli kısmı kültüre edilebilmekte ve endüstriyel olarak birçok alanda kullanılmaktadır. Endüstriyel alanda kullanılan bu mantarlar tıbbi alanda ve gıda sektörlerinde tercih edilmektedir (Chang ve Miles, 2004). 
Tat, aroma gibi organoleptik özelliklerinden dolayı gastronomi alanında tercih edilen makro mantarlar bulunmaktadır. Ayrıca mantarlar içerik olarak bakıldığında yüksek oranda suya sahiptir, katı kısım karbonhidrat ve lif yönünden zengin, vitamin, mineral, doymamış yağ asidi, enzimler, terpenoit, steroit, glikozit, alkoloit, kinon ve fenil propanoid türevleri gibi çok çeşitli bileşiklere sahiptir. Antitümör, antialerjik, antimutajenik, antiviral, antimikrobiyal, antiparazitik, prebiyotik aktivite, karaciğer koruyucu immün sistem güçlendirici, kolestrol düşürücü gibi etkileri olduğu kanıtlanmıştır (Barros ve ark., 2008; Synytsya ve ark., 2009; Kalac, 2012; Sulistiany ve ark., 2016).

Makromantarlar, morfolojik olarak şapka, sap, lamel ve köklere sahipken, bunların yanı sıra sporları bulunmaktadır. Sporlar makro mantarların taksonomik teşhislerinde önemli bir yere sahiptir. Basidiomycota filumu içerisinde yer alan Pleurotus türleri sporlarını basidya, Ascomycota filumu içerisinde yer alan Morchella türleri sporlarını aski adı verilen kese benzeri yapılar içerisinde üretmektedir. Mantarlar, Dünya'nın geri dönüşümcüsü ve filtresi olarak kabul edilmektedir. Bulundukları bölgelerdeki çevresel veya insan kaynaklı toksinleri detoksifiye, dekonstrükte ve biriktirme özelliklerine sahiptir (Pouliot, 2018).
Dünyada yaygın olarak üretimi yapılan mantarlar Agaricus bisporus, Lentinula edodes ve farklı Pleurotus türleridir (Yamaç ve Pekşen, 2016). Yapılan kültür çalışmasına göre kalan kompostun içeriği farklılık göstermektedir (Çatal ve Pekşen, 2020). Mantar üretimi sonrasında kalan kompostun değerlendirilmesi ve ekonomiye kazandırılmasına yönelik çalışmalar artarak devam etmektedir. Bu derlemede atık mantar kompostunun toprağın zenginleştirilmesi amacı ile kullanımı yanında özellikle diğer potansiyel kullanım alanları değerlendirilmiştir.

\section{ATIK MANTAR KOMPOSTU}

Kompost içeriğinin şapkalı mantarların üretimi esnasında mantar tarafından tüketilmesi sonucu arda kalan kompost, atık mantar kompostu olarak tanımlanmaktadır. Gelişimi geç olan mantar türleri dışında 2,5 hafta içerisinde primordiyum yapısı gözlenmeye başladığında bu kompost harcanmış olarak kabul edilmektedir (Rinker, 2017). Endüstriyel çapta mantar üretim tesislerinin en büyük problemlerinden bir tanesi atık mantar kompostlarıdır. Bu atık kompostlar önceleri imha edilirken daha sonralarda tekrar kullanılabilmesi yönünde birçok çaIışma yapılmış ve halen yapılmaktadır. Yapılan çalışmalar doğrultusunda atık mantar kompostunun ortalama kompozisyon verileri elde edilmiştir (Tablo 1) (Gerrits, 1987; Maher, 1988; Wuest ve Fahy, 1991).

Tablo 1. Atık mantar kompostu kompozisyonu

\begin{tabular}{|c|c|c|c|}
\hline & İrlanda (Maher 1988) & $\begin{array}{c}\text { Hollanda (Gerrits } \\
1987)\end{array}$ & $\begin{array}{c}\text { Amerika (Wuest ve } \\
\text { Fahy 1991) }\end{array}$ \\
\hline Kuru Madde (\%) & 35 & 35 & 43 \\
\hline Kül & 39 & 45 & 1,9 \\
\hline $\mathrm{N}$ & 2,8 & 2,4 & 0,4 \\
\hline $\mathrm{P}$ & 1,0 & 0,8 & 2,4 \\
\hline $\mathrm{K}$ & 2,0 & 2,8 & 4,9 \\
\hline $\mathrm{Ca}$ & 6,6 & 12,6 & 0,7 \\
\hline $\mathrm{Mg}$ & 0,5 & 0,5 & 333 \\
\hline $\mathrm{Mn}(\mathrm{mg} / \mathrm{kg})$ & 313 & & \\
\hline
\end{tabular}




\section{Atık Mantar Kompostunun Yaygın ve Geleneksel Kullanım Alanları}

Atık mantar kompostları organik madde açısından zengin olduklarında toprak yapısını iyileştirmede büyük faydası vardır bu yüzden atık mantar kompostları uygulamalarında ilk düşünülen gübre olarak kullanılmasıdır. Yapılan çok sayıda gübre uygulamasında atık mantar kompostlarının eklendiği topraklardan elde edilen mahsullerde verim artışı sağladığı gözlenmiştir (Maher, 1988).

Atık mantar kompostuna farklı inorganik bileşiklerin eklenmesiyle gübre kompleksi oluşturulabilmektedir. Bu gübre kompleksleri farklı mahsul üretiminde değerlendirilmiştir. Çeltik üretimi üzerinde yapılan bir çalışmada \%7 verim artışı gözlenmiştir (Meiqin, 2006). Güller üzerinde yapılan başka bir çalışmada parti başına çiçek sayısında artış ve hastalık insidanslarında düşüş (Yangjun, 2006), portakal ağaçları üzerinde yapılan başka bir çalışmada meyve veriminde artış ve hastalık insidanslarında düşüş gözlenmiştir (Shenggang, 2005). Atık mantar kompostunun gübre uygulamalarının yanı sıra bitki gelişimlerini teşvik edici hormonlarda üretilmiştir. Soya fasulyeleri üzerinde yapılan çalışmada, bu hormonlar soya fasulyelerine püskürterek uygulanmış sap ve yapraklarının daha güçlü olduğu ve hastalık insidanslarının düştüğü raporlanmıştır (Zhengfeng, 1997; Linyong, 2006).

Atık mantar kompostlarının gübre uygulamalarında bazı sorunlarla karşılaşılmıştır. Bu sorunlardan bir tanesi, Atık mantar kompostunun eklendiği toprakta makro mantarların gelişmesidir. Bu sorun, merkezi bir kompostlama tesisinde atık mantar kompostundan misellerin arındırılması ile çözülmüştür (Maher ve ark., 1993). Bir diğeri ise atık mantar kompostundaki yüksek potasyum seviyesinin bitkilerde stres durumuna sebep olmasıdır. Bu sorunun giderilmesi için atık mantar kompostlarında yüksek potasyum oranını azaltabilmek adına zeolit gibi malzemeler kullanılmıştır (Cock ve Taylor, 1965).

Biyoremediasyon; bakteri, mantar ve yeşil bitkiler gibi canlı organizmaların hava, toprak ve suda istenmeyen kirleticileri uzaklaştırmak veya etkisiz hale getirmek için kullanılmasıdır. Çevresel kirleticilerin yok edilmesi ve etkilerinin azaltılması üzerine atık mantar kompostları ile çalışmalar yapılmıştır (Gerrits, 1987).

Pleurotus atık mantar kompostunun atık suda ki bakır ve nikeli uzaklaştırdığı, zeytinyağı üretim tesisi atıklarında fenolik bileşiklerin toksiditesini azalttığı (Martirani ve ark., 1996), meyve suyu endüstrisinde ortaya çıkan atık sudan pestisitleri uzaklaştırdığı (Karas ve ark., 2015) raporlanmıştır.
Lentinula edodes atık mantar kompostu atık sulardaki kadmiyumun giderilmesinde (Chi ve ark., 2009), Ganoderma lucidium atık kompostu çeşitli organik toksinlerin uzaklaştırımasında (Liao ve ark., 2012) ve içme sularından florin giderilmesinde (Chen ve ark., 2015), Agaricus bisporus atık mantar kompostu topraktan çinko, kadmiyum ve kurşun toksiditesinin giderilmesinde (Shuman, 1998), bir çok tehlikeli atık maddenin degredasyonu, nitrifikasyonu, uzaklaştırılması, iyileştirilmesi için kullanılmıştır (Bazin ve ark., 1991; Chiu ve ark., 2009; Li ve ark., 2010).

Atık mantar kompostları hayvan yemlerine eklenerek selüloz, hemiselüloz ve lignin içeriklerini ekstrasellüler enzimleri ile ayrıştırdıkları için yemlerin kalitesini artırmaktadır. Ayrıca protein içerikleri yüksek olduğu için birçok hayvan yeminde kullanılmaktadır (Zeng ve ark., 2007). Atık mantar kompostlarının, demir, kalsiyum, çinko, magnezyum, protein, esansiyel amino asit gibi zengin içeriğinden dolayı tahıl ve kepek gibi ham yemlerin yerinin alabileceği ucuz ve besleyici bir hayvan yemi olabileceği düşünülmektedir (Hui ve ark., 2007).

Pleurotus ostreatus atık mantar kompostu üzerinde yapılan çalışmalar sonucunda sığır, tavşan, domuz gibi hayvanların yemlerinde kullanıldığında verimli sonuçlar elde edildiği raporlanmıştır. Domuzlarda yapılan bir çaıışmada atık mantar kompostları yem olarak kullanıımış ve hayvanlar üzerinde ki etkileri çalışılmıştır. Gebe domuzların atık mantar kompostu ile beslenmesi sağlanmış ve ardından normal yem yiyen gebe domuzlar ile karşılaştırılmıştır. Atık mantar kompostu ile beslenen domuzların yavrularının daha sağlıklı, kilolu, ishal ve ölüm oranlarının düşük olduğu tespit edilmiştir (Hao-Bo ve ark., 2007). Bir diğer çalışmada ise yine Pleurotus ostreatus türünün atık mantar kompostları sığır yemlerine eklenmiştir. Atık mantar kompostu eklenen yem ile beslenen sığırların beslenmeyenlere göre üreme, süt verimi ve tedavi yanıtlarında \%6'ya kadar artış olduğu ayrıca büyükbaş hayvanların rumenlerindeki mikroorganizma florasının iyi yönde etkilendiği tespit edilmiştir (Liang ve ark., 2001).

Atık mantar kompostları biyoyakıt ve alternatif yakıt kaynağı olarak kullanılabilmektedir. Pleurotus ostreatus ve Lentinula edodes türlerinin atık mantar kompostları alternatif yakıt ve biyogaz kaynağı olarak incelenmiştir (Kapu ve ark., 2012; Tumwasorn ve ark., 1980). Farklı türlere ait atık mantar kompostları içerisinde metan gazı üreten bakterilerin uzun süre yaşayabileceği ve yayılabileceği en ideal malzemeleri barındırmaktadır. Biyogaz üretimi için uygun ortam sağlayan Agaricus bisporus, Lentinula edodes ve Auricularia auricula gibi atık mantar kompostları üzerine çalışmalar yapılmıştır. Bu çalışmalara göre 
$5 \mathrm{~kg}$ atık mantar kompostunun 3-5 kişilik bir ailenin günlük biyogaz intiyacını karşılayabileceği saptanmıştır (Songlin, 2002; Najafi ve ark., 2019).

Atık mantar kompostları aktif karbonun kömürleşmesi (Ma ve ark., 2014), ısıya dayanıklı formüller (Donnell ve Busta, 1980), lignoselülozik enzim kaynağı (Ball ve Jackson, 1995; Phan ve Sabaratnam, 2012), biyo-aşılayıcıların hazırlanması için taşıyıcı malzeme (Bahl ve Jauhri, 1986; Bahl ve ark., 1989), tuğlalar için yalıtım malzemesi ve hayvanlar için yatacak yer (Durrell ve ark., 1997; Beattie ve ark., 2001; Tajbakhsh ve ark., 2008; Velascoa ve ark., 2014), beton takviye malzemesi (Russell ve ark., 2005), vermikültür (Edwards ve ark., 1985; Tajbakhsh ve ark., 2008) için kullanılmıştır. Pleurotus türleri atık mantar kompostları hücre dışı enzim üretimi (Tan ve Wahab, 1997; Phan ve Sabaratnam, 2012), nanoparçacık üretimi (Vigneshwaran ve ark., 2007), peynir ve ayran üretiminde kullanılan Lactococcus lactis bakterisinin üretimi (Wu ve ark., 2014) ve süper emici reçinelerin üretilmesi için (Ding ve Gong, 2013) için kullanımıştır. Flammulina türlerinin atık mantar kompostları biyolojik pestisit olan Bacillus thuringiensis'in çoğaltılması için araştırılmıştır (Wu ve ark., 2013, Wu ve ark., 2014).

\section{Ekstrasellüler Enzim Kaynağı Olarak Atık Mantar Kompostu}

Yüksek biyolojik aktiviteye sahip atık ürünlerin enzim kaynağı olarak değerlendirilmesi hem bu atıkların giderilmesinde hem de birim değeri yüksek ürün üretilmesinde çevreci bir yaklaşım sunmaktadır. Şapkalı mantarlar kültüre edilirken besin maddesi olarak kompost içindeki kompleks bileşikleri kullanabilmek için bol miktarda ekstrasellüler enzim üretmektedir. Üretim süreci sonunda atık mantar kompostu içerisinde bu enzimlerin bir kısmı kalmaktadır ve bu nedenle atık mantar kompostu enzim üretimi için değerlendirilebilecek biyolojik ajan grupları içerisinde yer almaktadır. Atık mantar kompostlarından elde edilebilen endüstriyel öneme sahip enzimler bulunmaktadır.

Atık mantar kompostunun ekstrasellüler enzim kaynağı olarak değerlendirilmesine yönelik çalışmalar son yıllarda artmaktadır. Bu çalışmalarda kültürü yapılan mantar türünün atık mantar kompostunun içeriğindeki enzim çeşitliliğini, canlı fungal ve bakteriyal biyomas miktarını ve çeşitliliğini ve lignoselülozik bileşik miktarını etkilediği belirlenmiştir (Yamaç ve Pekşen, 2016).

Atık mantar kompostlarından elde edilebilecek olan enzimlerden olan lakkaz enzimi, benzen halkalarını, azo boyaları, fenolik bileşikleri, aromatik olmayan lignin içerikli bileşikleri oksitlemektedir. Endüstriyel üretimler sonucunda ortaya çıkan atıklardaki kirleticilerinin etkilerinin azaltılmasında ve uzaklaştırılmasında, meyve suyu, bira, şarap endüstrisinde stabilizasyonda, renk ve bulanıklığın giderilmesinde, fırın endüstrisinde hamur kalitesinin ve hacminin arttırılmasında, kağıt endüstrisinde kağıt hamurunun ağartılmasında, gıda maddelerinde aroma artırıcı olarak kullanılmaktadır (Christopher ve ark., 2014; Singh ve ark.,2014; Chandra ve Chowdhary, 2015; Sondhi ve ark., 2015; Mathews ve ark., 2016; Saxena ve Chauhan, 2016; Wang ve Zhao, 2016; Chauhan ve ark., 2017; Bilal ve ark, 2019; Singh ve Gupta, 2020).

Lignin peroksidaz (LiP), birçok ksenobiyotiğin degredasyonunda rol oynamaktadır. Bu enzim toprak detoksifikasyonunda, atık sulardaki kirleticilerin degredasyonunda, etanol üretiminde, kozmetik ürünlerinde, gıdaların raf ömürlerinin uzatılmasında kullanılmaktadır (Osma ve ark.,2010; Draelos, 2015; Singh, 2015; Falade ve ark., 2017).

Manganez peroksidaz (MnP) enzimi, ksenobiyotiklerin degredasyonunu sağlamaktadır. Bu enzimler, meyve suyu, şarap, bira endüstrisinde berraklaştırıcı olarak, gıdalarda renk iyileştirici ve aroma arttırıcı olarak kullanılmaktadır (Maciel ve ark.,2010; Vrsanska ve ark., 2015; Velioglu ve Ozturk, 2015; Chowdhary ve ark., 2019).

Ksilanaz enzimi, uzun zincirli polisakkarit iskeletlerin parçalamasının yanı sıra lignin degredasyonunu sağlamaktadır. Meyve suyu, şarap ve bira endüstrisinde berraklaştırma ve stabilizasyonda, kağıt hamurunun ağartılmasında, gıda raf ömürlerinin uzatılmasında kullanılmaktadır (Michelin ve ark., 2014; Mandal, 2015; Moreira ve Filho, 2016; Raveendran ve ark., 2018).

Proteaz enzimi, proteinlerin daha küçük peptidlere hidrolize olmasını, protein-protein etkileşimlerinin modüle olmasını sağlamaktadır. Proteazlar, deterjan endüstrisinde leke çıkarıcı, tekstil endüstrisinde liflerin gam giderilmesinde, hayvan yemlerinin kalitesinin arttırımasında, fırın endüstrisinde hamur kalitesini arttırmak için, ilaç endüstrisinde terapötik ajanlar olarak kullanılmaktadır (Kirk ve ark., 2002; Jerica ve Janko, 2012; Cobos ve Diaz, 2015; Salinas ve ark., 2015; Zarei ve ark., 2015; Hussain ve ark., 2017; Liu ve Kokare, 2017; Palomba ve ark., 2017; Santini ve ark., 2017).

Amilaz enzimi, nişastanın primer gruplara hidrolize olmasını sağlamaktadır. Amilaz enzimleri deterjan endüstrisinde leke çıkarıcı olarak, etanol üretiminde, fırın endüstirisinde hamur kalitesinin arttırılmasında, hayvan yemlerinin kalitesinin arttırılmasında, Kağıt endüstrisinde mukavemet artııılmasında kullanılmaktadır (Kirk ve ark., 2002; Mitidieri ve ark., 2006; Ahlawat ve ark., 2009; Chi ve ark., 2009; Ghorai ve ark., 2009; Hmidet ve 
ark., 2009; Mukherjee ve ark., 2010; Prakash ve Jaiswal, 2010; Silva, 2014; Sundarram ve Murty, 2014; Pundir, 2015; Saini ve ark., 2017; Park ve ark., 2018; Satya ve Swasti, 2019).

Selülazlar, selülozik bileşiklerin parçalanmasında kompleks enzim grubu olarak katalizleme yapmaktadır. Kristallin selülozun değredasyonunda endoglukanaz, ekzoglukanaz ve $\beta$-glukosidaz olmak üzere farklı selülazlar kompleks şekilde çalışmaktadırlar. Selülazlar bitki patojenlerinin ve bitki hastalıklarının kontrolünde, hayvan yemi kalitesini arttırılmasında, meyve suyu, bira, şarap endüstrisinde aroma arttırıcı, renk iyileştirici, fırın endüstrisinde hamur kalitesini arttırıcı olarak ve deterjan endüstirisinde kullanılmaktadır (Liming ve Xueliang, 2004; Kuhad ve ark., 2011; Karmakar ve Ray, 2011; Urbaniec ve Bakker 2015; Kuhad ve ark., 2016; Shah ve ark.,2017; Soccol ve ark., 2017; Raveendran ve ark., 2018).

\section{Antimikrobiyal Madde Kaynağı Olarak Atık Mantar Kompostu}

Mantarlar kendi doğal ortamlarında aynı alanı ve kaynakları paylaştıkları, hızlı şekilde üreyen bakterilere karşı rekabet güçlerinin artmasını sağlayan antimikrobiyal etki gösteren bileşenler üretmektedir. Mantarların ürettikleri bu antimikrobiyal maddeler ekstrasellüler bileşiklerdir ve bu bileşikler insan sağlığı için hastalıkların tedavisinde büyük önem taşımaktadır. Farklı doğal kaynaklardan elde edilen antimikrobiyaller sadece hastalıklardan korunma ya da iyileşme amacı ile değil, gıdaların raf ömürlerinin uzatılması veya gıda kaynaklı hastalıkların önlenmesi için de kullanılmaktadır (Tajkarimi ve ark., 2010).

Mikroorganizmaların mevcut antimikrobiyallere olan dirençlerinin artması sonucu, hali hazırda bulunan antimikrobiyallerden başka çeşitli kaynaklardan elde edilebilecek olan antimirobiyallerin arayışına sebep olmaktadır (Levy ve Marshall, 2004). Doğal antimikrobiyallerin önemi penisilinin keşfi ile ortaya konulmuştur (Spiteller, 2008).

Mantarlar üzerinde yapılan çalışmalarda antimikrobiyal etkileri raporlanmıştır. Basidiomycetes makro funguslarından grifolin (Hirata ve Nakanishi, 1950), skorodonin, strobilurin C (Anke ve ark., 1980), ganomisin (Mothana ve ark., 2000), mikaseol (Zahid ve ark., 2006), plöromutilin (Kavanagh ve ark., 1951) gibi antimikrobiyal maddeler izole edilmiştir. Farklı mantar türlerinden ve atık mantar kompostlarından elde edilen ekstraktlar çok sayıda gram pozitif ve gram negatif bakterilere ve mayaya uygulanmıştır (Tablo 2). Ekstraktların bu mikroorganizmalar üzerinde inhibe edici etkiye sahip olduğu gözlenmiştir (Wolff ve ark., 2008; Alves ve ark., 2013; Glamoclija ve ark., 2018). Atık mantar kompostlarının antimikrobiyal etkisi ile ilgili pek fazla çalışmaya rastlanmamıştır.

Tablo 2. Bazı mantarların antimikrobiyal aktivitesi (Glamoclija ve ark., 2018)

\begin{tabular}{|c|c|c|}
\hline Mantar & Ekstrakt tipi & Antimikrobiyal aktivite \\
\hline \multirow{3}{*}{ Agaricus bisporus } & \multirow{2}{*}{ Metanol } & $\begin{array}{l}\text { Antibakteriyal } \\
\text { İnhibisyon zonu 4-23 mm }\end{array}$ \\
\hline & & $\begin{array}{l}\text { Antifungal } \\
\text { İnhibisyon zonu 8-21 mm }\end{array}$ \\
\hline & Aseton & $\begin{array}{l}\text { Antibakteriyal } \\
\text { İnhibisyon zonu } 10-17,77 \mathrm{~mm}\end{array}$ \\
\hline \multirow{4}{*}{ Agaricus blazei } & \multirow{2}{*}{ Metanol } & $\begin{array}{l}\text { Antibakteriyal } \\
\text { Minimum inhibisyon konsantrasyonu } 0,1-2,3 \mathrm{mg} / \mathrm{ml}\end{array}$ \\
\hline & & $\begin{array}{l}\text { Antifungal } \\
\text { Minimum inhibisyon konsantrasyonu } 0,1-1,25 \mathrm{mg} / \mathrm{ml}\end{array}$ \\
\hline & \multirow{2}{*}{ Etanol } & $\begin{array}{l}\text { Antibakteriyal } \\
\text { Minimum inhibisyon konsantrasyonu } 0,04-1,15 \mathrm{mg} / \mathrm{ml}\end{array}$ \\
\hline & & $\begin{array}{l}\text { Antifungal } \\
\text { Minimum inhibisyon konsantrasyonu } 0,15-3,125 \mathrm{mg} / \mathrm{ml}\end{array}$ \\
\hline \multirow{4}{*}{ Agaricus campestris } & \multirow{2}{*}{ Metanol } & $\begin{array}{l}\text { Antibakteriyal } \\
\text { Minimum inhibisyon konsantrasyonu } 0,58-2,34 \mu \mathrm{g} / \mathrm{ml}\end{array}$ \\
\hline & & $\begin{array}{l}\text { Antifungal } \\
\text { Minimum inhibisyon konsantrasyonu } 0,39-6,25 \mu \mathrm{g} / \mathrm{ml}\end{array}$ \\
\hline & \multirow{2}{*}{ Etanol } & $\begin{array}{l}\text { Antibakteriyal } \\
\text { Minimum inhibisyon konsantrasyonu } 0,03-2,34 \mu \mathrm{g} / \mathrm{ml}\end{array}$ \\
\hline & & $\begin{array}{l}\text { Antifungal } \\
\text { Minimum inhibisyon konsantrasyonu } 0,1-3,12 \mu \mathrm{g} / \mathrm{ml}\end{array}$ \\
\hline
\end{tabular}


Atık Mantar Kompostunun Geleneksel ve Yeni Kullanım Alanları

\begin{tabular}{|c|c|c|}
\hline \multirow{4}{*}{ Agaricus macroporus } & \multirow{2}{*}{ Metanol } & $\begin{array}{l}\text { Antibakteriyal } \\
\text { Minimum inhibisyon konsantrasyonu } 0,4-1,15 \mu \mathrm{g} / \mathrm{ml}\end{array}$ \\
\hline & & $\begin{array}{l}\text { Antifungal } \\
\text { Minimum inhibisyon konsantrasyonu } 0,4-3 \mu \mathrm{g} / \mathrm{ml}\end{array}$ \\
\hline & \multirow[b]{2}{*}{ Etanol } & $\begin{array}{l}\text { Antibakteriyal } \\
\text { Minimum inhibisyon konsantrasyonu } 0,35-1,7 \mu \mathrm{g} / \mathrm{ml}\end{array}$ \\
\hline & & $\begin{array}{l}\text { Antifungal } \\
\text { Minimum inhibisyon konsantrasyonu } 0,5-2,34 \mu \mathrm{g} / \mathrm{ml}\end{array}$ \\
\hline \multirow{4}{*}{ Agaricus bitorquis } & \multirow{2}{*}{ Metanol } & $\begin{array}{l}\text { Antibakteriyal } \\
\text { Minimum inhibisyon konsantrasyonu } 0,29-2,34 \mu \mathrm{g} / \mathrm{ml}\end{array}$ \\
\hline & & $\begin{array}{l}\text { Antifungal } \\
\text { Minimum inhibisyon konsantrasyonu } 0,78-3,12 \mu \mathrm{g} / \mathrm{ml}\end{array}$ \\
\hline & \multirow{2}{*}{ Etanol } & $\begin{array}{l}\text { Antibakteriyal } \\
\text { Minimum inhibisyon konsantrasyonu } 0,23-1,17 \mu \mathrm{g} / \mathrm{ml}\end{array}$ \\
\hline & & $\begin{array}{l}\text { Antifungal } \\
\text { Minimum inhibisyon konsantrasyonu } 0,39-3,12 \mu \mathrm{g} / \mathrm{ml}\end{array}$ \\
\hline \multirow{4}{*}{ Coprinus comatus } & \multirow{2}{*}{ Metanol } & $\begin{array}{l}\text { Antibakteriyal } \\
\text { Minimum inhibisyon konsantrasyonu } 0,75-3 \mathrm{mg} / \mathrm{ml}\end{array}$ \\
\hline & & $\begin{array}{l}\text { Antifungal } \\
\text { Minimum inhibisyon konsantrasyonu } 0,75-3 \mathrm{mg} / \mathrm{ml}\end{array}$ \\
\hline & \multirow[b]{2}{*}{ Su } & $\begin{array}{l}\text { Antibakteriyal } \\
\text { Minimum inhibisyon konsantrasyonu } 13-52 \mathrm{mg} / \mathrm{ml}\end{array}$ \\
\hline & & $\begin{array}{l}\text { Antifungal } \\
\text { Minimum inhibisyon konsantrasyonu } 13-52 \mathrm{mg} / \mathrm{ml}\end{array}$ \\
\hline Grifola frondosa & Sıcak Alkali & $\begin{array}{l}\text { Antibakteriyal } \\
\text { Minimum inhibisyon konsantrasyonu } 0,02-2,5 \mathrm{mg} / \mathrm{ml}\end{array}$ \\
\hline \multirow{4}{*}{ Laetiporus sulphureus } & \multirow[b]{2}{*}{ Metanol } & $\begin{array}{l}\text { Antibakteriyal } \\
\text { Minimum inhibisyon konsantrasyonu } 0,9-3,6 \mathrm{mg} / \mathrm{ml}^{-1}\end{array}$ \\
\hline & & $\begin{array}{l}\text { Antifungal } \\
\text { Minimum inhibisyon konsantrasyonu } 1,25-4,5 \mathrm{mg} / \mathrm{ml}^{-1}\end{array}$ \\
\hline & \multirow{2}{*}{ Polisakkarit } & $\begin{array}{l}\text { Antibakteriyal } \\
\text { Minimum inhibisyon konsantrasyonu } 0,4-3,1 \mathrm{mg} / \mathrm{ml}^{-1}\end{array}$ \\
\hline & & $\begin{array}{l}\text { Antifungal } \\
\text { Minimum inhibisyon konsantrasyonu } 0,5-4 \mathrm{mg} / \mathrm{ml}^{-1}\end{array}$ \\
\hline \multirow{3}{*}{ Lentinula edodes } & Su & $\begin{array}{l}\text { Antibakteriyal } \\
\text { Minimum inhibisyon konsantrasyonu 5->50 mg/ml } \\
\text { İnhibisyon Zonu: } 15-21,2 \mathrm{~mm}\end{array}$ \\
\hline & Etil asetat & $\begin{array}{l}\text { Antibakteriyal } \\
\text { Minimum inhibisyon konsantrasyonu } 0,1-2 \mathrm{mg} / \mathrm{ml}\end{array}$ \\
\hline & Kloroform & $\begin{array}{l}\text { Antibakteriyal } \\
\text { Minimum inhibisyon konsantrasyonu } 0,01->1,5 \mathrm{mg} / \mathrm{ml}\end{array}$ \\
\hline \multirow[t]{2}{*}{ Morchella esculenta } & Metanol & $\begin{array}{l}\text { Antibakteriyal } \\
\text { Minimum inhibisyon konsantrasyonu } 0,02->10 \mathrm{mg} / \mathrm{ml} \\
\text { İnhibisyon Zonu: } 6,16-8,34 \mathrm{~mm}\end{array}$ \\
\hline & Etanol & $\begin{array}{l}\text { Antibakteriyal } \\
\text { Minimum inhibisyon konsantrasyonu 0,8-50 mg/ml }\end{array}$ \\
\hline \multirow{3}{*}{ Morchella conica } & \multirow{2}{*}{ Metanol } & $\begin{array}{l}\text { Antibakteriyal } \\
\text { Minimum inhibisyon konsantrasyonu } 0,7-7,5 \mathrm{mg} / \mathrm{ml}\end{array}$ \\
\hline & & $\begin{array}{l}\text { Antifungal } \\
\text { Minimum inhibisyon konsantrasyonu } 0,78-12,5 \mathrm{mg} / \mathrm{ml}\end{array}$ \\
\hline & Etanol & $\begin{array}{l}\text { Antibakteriyal } \\
\text { İnhibisyon Zonu: 4-29mm }\end{array}$ \\
\hline Meripilus giganteus & Metanol & Antibakteriyal \\
\hline
\end{tabular}


Atık Mantar Kompostunun Geleneksel ve Yeni Kullanım Alanları

\begin{tabular}{|c|c|c|}
\hline & & $\begin{array}{l}\text { Minimum inhibisyon konsantrasyonu } 0,012-2,5 \mathrm{mg} / \mathrm{ml} \\
\text { İnhibisyon Zonu:8,5-17,5mm }\end{array}$ \\
\hline & & $\begin{array}{l}\text { Antifungal } \\
\text { Minimum inhibisyon konsantrasyonu 0,025-0,3 mg/ml }\end{array}$ \\
\hline & & $\begin{array}{l}\text { Antibakteriyal } \\
\text { İnhibisyon zonu } 1-30,66 \mathrm{~mm}\end{array}$ \\
\hline & Sulu & $\begin{array}{l}\text { Antifungal } \\
\text { İnhibisyon zonu } 20,66-33,33 \mathrm{~mm}\end{array}$ \\
\hline & & $\begin{array}{l}\text { Antibakteriyal } \\
\text { Minimum inhibisyon konsantrasyonu 5-8 mg/ml } \\
\text { İnhibisyon Zonu:5-10,5mm }\end{array}$ \\
\hline Pleurotus ostreatus & Metanol & $\begin{array}{l}\text { Antifungal } \\
\text { Minimum inhibisyon konsantrasyonu } 4 \text { mg/ml } \\
\text { İnhibisyon Zonu: 8-15,5 mm }\end{array}$ \\
\hline & Etanol & $\begin{array}{l}\text { Antibakteriyal } \\
\text { İnhibisyon zonu } 6,75-21,83 \mathrm{~mm}\end{array}$ \\
\hline & Etil asetat & $\begin{array}{l}\text { Antibakteriyal } \\
\text { İnhibisyon zonu } 7,1-13,43 \mathrm{~mm}\end{array}$ \\
\hline & Hekzan & $\begin{array}{l}\text { Antibakteriyal } \\
\text { İnhibisyon zonu } 11,09-24,56 \mathrm{~mm}\end{array}$ \\
\hline & Kloroform & $\begin{array}{l}\text { Antibakteriyal } \\
\text { İnhibisyon zonu } 10-17 \mathrm{~mm}\end{array}$ \\
\hline & & $\begin{array}{l}\text { Antibakteriyal } \\
\text { Minimum inhibisyon konsantrasyonu } 0,2-20,4 \mathrm{mg} / \mathrm{ml}\end{array}$ \\
\hline Polyporus squamosus & Metanol & $\begin{array}{l}\text { Antifungal } \\
\text { Minimum inhibisyon konsantrasyonu } 0,4-3,13 \mathrm{mg} / \mathrm{ml}\end{array}$ \\
\hline & Etanol & $\begin{array}{l}\text { Antibakteriyal } \\
\text { Minimum inhibisyon konsantrasyonu } 6,3-50 \mathrm{mg} / \mathrm{ml}\end{array}$ \\
\hline
\end{tabular}

\section{SONUÇLAR}

Ülkemizde ve dünya genelinde her geçen yıl artan miktarlarda şapkalı mantar üretimi yapılmaktadır. Zirai atıkların değerlendirilmesi ve maddi değeri yüksek ürüne dönüştürülmesi ve böylelikle üretime kazandırılması çok önemlidir. Yaptığımız çalışma üretim sonrasında kalan kompost materyalinin farklı alanlarda kullanım potansiyeli olup olmadığı hakkında fikir vermesi yönünden önemlidir.

Gıda olarak tat, aroma ve besin değeri yönünden mantarlar tercih edilmektedir. Kompost ekstraktlarının antimikrobiyal özellikte olması sağlık sektörü ile güvenilir ve fonksiyonel gıda üretimini akla getirse de ayırma ve saflaştırma işlemleri yönünden ekonomik olup olmadığı değerlendirilmelidir.

Enzimatik karakterizasyonunun tam olarak yapılması ile ekstraktların kullanımı daha olası görülmektedir. Bu ekstraktlar;

$\checkmark$ Renk gideriminde

$\checkmark$ Hemiselülozik ve lignin içeren atıklardan biyoyakıt üretiminde $\checkmark$ Meyve sularında bulanıklılık gideriminde

$\checkmark$ Çiftlik hayvanlarının yemlerinin sindirilebilirliğinin arttırılmasında

$\checkmark$ Kağıt endüstrisinde

$\checkmark$ Tekstil endüstrisinde kumaş kalitesinin arttırılmasinda

$\checkmark$ Atık arıtımında ve diğer sektörlerde değerlendirilebilinir.

Sonuç olarak; özellikle büyük çapta üretimin yapıldığı tesislerde ortaya çıkan kompostun sadece gübre olarak değil, bu kompostlardan elde edilecek ekstraktların farklı alanlarda kullanım yolları araştırımalı ve değerlendirilmelidir.

\section{TEŞEKKÜR}

Burdur Mehmet Akif Ersoy Üniversitesi Bilimsel Araştırma Projeleri Koordinatörlüğü'ne (0564-YL-19) teşekkür ederiz. 


\section{KAYNAKLAR}

Ahlawat, S., Dhiman, S.S., Battan, B., Mandhan, R.P., Sharma, J. (2009). Pectinase Production by Bacillus subtilis and Its Potential Application in Biopreparation of Cotton and Micropoly Fabrica. Process Biochemistry 44: 521-526.

Alves, M.J., Ferreira, I.C.F.R., Dias, J., Teixeira, V., Martins, A. (2013). A Review on Antifungal Activity of Mushroom Extracts and Isolated Compounds. Current Topics in Medicinal Chemistry 13(21): 2648-2659.

Anke, T., Kupka, J., Schramm, G., Steglich, W. (1980). Antibiotics from Basidiomycetes. X. Scorodonin, A New Antibacterial and Antifungal Metabolite From Marasmius Scorodonius. The Journal of Antibiotics 33: 463-467.

Bahl, N., Gupta, M., Jauhri, K.S., (1989). The Development of High-quality Inoculants From Spent Compost. Mushroom Science 12(1): 427-431.

Bahl, N., Jauhri, K.S. (1986). Spent Compost as A Carrier for Bacterial Inoculant Production. In: P.J. Wuest, D.J. Royse, R.B. Beelman (Eds). Proceedings of International Symposium on Scientific and Technical Aspects of Cultivating Edible Fungi. The Pennsylvania State University, 63-68.

Ball, A.S., Jackson, A.M., (1995). The Recovery of Lignocellulose-degrading Enzymes From Spent Mushroom Substrate. Bioresource Technology 54(3): 311-314.

Barron, G.L., Thorn, R.G. (1987). Destruction of Nematodes by Species of Pleurotus, Canadian Journal Botany 64: 774-778.

Barros, L., Cruz, T., Baptista, P., Estevinho, L.M., Ferreira, I.C.F.R. (2008). Wild and Commercial Mushrooms As Source of Nutrients and Nutraceuticals. Food Chemistry Toxicology 46: 2742-2747.

Beattie, V.E., Sneddon, I.A., Walker, N., Weatherup, R.N. (2001). Environmental Enrichment of Intensive Pig Housing Using Spent Mushroom Compost. Animal Science 72: 35-42.

Bilal, M., Adeel, M., Rasheed, T., Zhao, Y., lqbal, H.M., (2019). Emerging Contaminants of High Concern and Their Enzyme-assisted Biodegradation A Review. Environment International 124: 336-353.

Chandra, R., Chowdhary, P. (2015). Properties of Bacterial Laccases and Their Application in Bioremediation of Industrial Wastes. Environmental Science Processess and Impacts 17: 326-342.

Chang, S.T., Miles, P.G. (2004). Mushrooms: Cultivation, Nutritional Value, Medicinal Effect, and Environmental Impact. CRC Press, 2. Baskı.

Chauhan, P.S., Goradia, B., Saxena, A. (2017). Bacterial Laccase: Recent Update on Production, Properties and Industrial Applications. Biotechnology 7: 323.

Chen, G.J., Peng, C.Y., Fang, J.Y., Dong, Y.Y., Zhu, X.H., Cai, H.M. (2015). Biosorption of Fluoride from Drinking Water Using Spent Mushroom Compost Biochar Coated with Aluminum Hydroxide. Desalination and Water Treatment 111.

Chi, M., Chen, Y., Wu, T., Lo, H., Lin, L. (2009). Engineering of a Truncated $\alpha$-amylase of Bacillus sp. Strain TS-23 for the Simultaneous Improvement of Thermal and Oxidative Stabilities. Journal of Bioscience and Bioengineering 109(6): 531- 8.
Chi, Z., Chi, Z., Liu, G., Wang, F., Ju, L., Zhang, T. (2009). Saccharomycopsis fibuligera and its Applications in Biotechnology. Biotechnology Advances 27: 423-431.

Chiu, S.W., Gao, T., Chan, C.S.S., Ho, C.K.M. (2009). Removal of Spilled Petroleum in Industrial Soils by Spent Compost of Mushroom Pleurotus pulmonarius. Chemosphere 75: 837-842.

Chowdhary, P., More, A., Yadav, A., Bharagava, R.N. (2019). Ligninolytic Enzymes: An Introduction and Applications in the Food Industry. Enzymes in Food Biotechnology 181195.

Christopher, L.P., Yao, B., Ji, Y. (2014). Lignin Biodegradation with Laccase-mediator Systems. Frontiers in Energy Research 2: 1-13.

Cobos, Á., Díaz, O. (2015). Chemical Composition of Meat and Meat Products. In: Cheung, P.C.K., Mehta, B.M. (Eds.), Handbook of Food Chemistry. Springer, Berlin Heidelberg, Berlin, Heidelberg, 471-510.

Cock, L. J., Taylor R. E. (1965). The Effect of TBA Residues in Compost on the Growth of Mushrooms and Subsequently on Tomatoes and Cucumbers. Plant Pathology 14: 105108.

Çatal, S., Pekşen A. (2020). Physical, Chemical and Biological Properties of Spent Mushroom Substrates of Different Mushroom Species. Acta Horticulturae 59(1): 353-360.

Ding, R., Gong, K. (2013). Super-absorbent Resin Preparation Utilizing Spent Mushroom substrates. Journal of Applied Polymer Science 130(2): 1098-1103.

Donnell, L.S., Busta, F.F. (1980). Heat Resistance of Desulfotomaculum Nigrificans Spores in Soy Protein Infant Formula Preparations. Applied and Environmental Microbiology 40(4): 721-725.

Draelos, Z.D. (2015). A Split-face Evaluation of A Novel Pigment-lightening Agent Compared With No Treatment and Hydroquinone. Journal of the American Academy of Dermatology, 72: 105- 107.

Durrell, J., Sneddon, I.A., Beattie, V.E. (1997). Effects of Enrichment and Floor Type on Behaviour of Cubicle Loosehoused Dry Sows. Animal Welfare 6(4): 297-308.

Edwards, C.A., Burrows, I., Fletcher, K.E., Jones, B.A. (1985). The Use of Earthworms for Composting Farm Wastes. In: JKR Gasser (Ed.), Composting of Agricultural and Other Wastes. Elsevier Applied Science Publishers: London, 229-242.

Gerrits, J.P.G. (1987). Compost for Mushroom Production and Its Subsequent Use for Soil Improvement. In M. de Bertoldi, M. P. Ferranti, P. L'Hermite and F. Zucconi (eds) Compost: Production, Quality and Use. Elsevier Applied Science, London, 431-439.

Ghorai, S., Banik, S.P., Verma, D., Chowdhury, S., Mukherjee, S., Khowala, S. (2009). Fungal Biotechnology in Food and Feed Processing. Food Research International 42: 577587.

Glamoclija, J., Kosticc, M., Sokovicc, M. (2018). Antimicrobial and Hepatoprotective Activities of Edible Mushrooms. Biology of Macrofungi, 81-113.

Hao-bo, L., Yun-ying, G.A.O., Jin-min, L.E.I., Xin-nian, H.E., Xiao-ping, W.A.N.G., Lin- feng H. (2007). Influence of Short-Term Fattening Effects of Feeding with Waste Material from Lentinus Edodes(WMLE) on Qinshan Crossbred Steers, Journal of Henan Agricultural University, 04. 
Hirata, Y., Nakanishi, K. (1950). Grifolin, An Antibiotic from A Basidiomycete. Journal Biological Chemistry 184: 135144.

Hmidet, N., El-Hadj Ali, N., Haddar, A., Kanoun, S., Alya, S., Nasri, M. (2009). Alkaline Proteases and Thermostable $\alpha-$ amylase Co-produced by Bacillus licheniformis NH1: Characterization and Potential Application as Betergent Additive. Biochemical Engineering Journal 47: 71-79.

Hui, Z., Jianhua, L., Jianqing, D., Meiyuan, C., Yi, C. (2007). The Alternative Uses of Spent Mushroom Compost, Book Chapter; Conference Paper: Mushroom Biology and Mushroom Products. Proceedings of the Sixth International Conference on Mushroom Biology and Mushroom Products, Bonn, Germany, 48: 231-245.

Hussain, F., Kamal, S., Rehman, S., Azeem, M., Bibi, I., Ahmed, T., lqbal, H.M.N. (2017). Alkaline Protease Production Using Response Surface Methodology, Characterization and Industrial Exploitation of Alkaline Protease of Bacillus subtilis sp. Catalysis Letters 147(5): 1204-1213.

Jerica, S., Janko, K. (2012). Microbial and Fungal Protease Inhibitors Current and Potential Applications. Microbial Biotechnology 93(4): 1351-1375.

Kalac, P. (2012). Chemical Composition and Nutritional Value of European Species of Wild Growing Mushrooms, In: Mushrooms: Types, Properties and Nutrition, (S. Andres and N. Baumann Ed.), Nova Science Publishers.

Kapu, N.U.S., Manning, M., Hurley, T.B., Voigt, J., Cosgrove, D.J., Romaine, C.P. (2012). Surfactant-assisted Pretreatment and Enzymatic Hydrolysis of Spent Mushroom Compost for the Production of Sugars. Bioresource Technology 114: 399-405.

Karas, P., Metsoviti, A., Zisis, V., Ehaliotis, C., Omirou, M., Papadopoulou, E.S. (2015). Dissipation, Metabolism and Sorption of Pesticides Used in Fruit-packaging Plants: Towards An Optimized Depuration of Their Pesticide-contaminated Agro-industrial Effluents. Science of the Total Environment, 530-531, 129-139.

Karmakar, M., Ray, R.R. (2011). Current Trends in Research and Application of Microbial Cellulases. Reseach Journal Microbiology 6: 41-53.

Kavanagh, F., Hervey, A., Robbins, W.J. (1951). Antibiotic Substances from Basidiomycetes.8. Pleurotus multilus (Fr.) Sacc. and Pleurotus passeckerianus Pilat. Proceedings of the National Academy Sciences of the United States of America 37: 570-574.

Kirk, O., Borchert, T.V., Fuglsang, C.C. (2002). Industrial Enzyme applications. Current Opinion in Biotechnology, 13(4): 345-351.

Kuhad, R.C., Deswa, D., Sharma, S., Bhattacharya, A., Jain, K.K., Kaur, A., Karp, M. (2016). Revisiting Cellulase Production and Redefining Current Strategies Based on Major challenges. Renewable and Sustainable Energy Reviews 55: 249-272.

Kuhad, R.C., Gupta, R., Singh, A. (2011). Microbial Cellulases and Their Industrial Applications. Enzyme Research 1-10.

Levy, S.B., Marshall, B. (2004). Antibacterial Resistance Worldwide: Causes, Challenges and Responses. Nature Medicine 10: 122-129.

Li, X., Lin, X., Zhang, J., Wu, Y., Yin, R., Feng, Y., Wang, Y. (2010). Degradation of Polycyclic Aromatic Hydrocarbons by Crude Rxtracts From Spent Mushroom Substrate and
Its Possible Mechanisms. Current Microbiology 60: 336342.

Liang, X.W., Yao L., Liu Q. Hua, B.R.H. (2001). Ruminal Degradability of Organic Material and Cell Wall Constituent of Waste Material From Fungal Culture by Different Treatments in Nylon Bags for Cattle. Journal of Fujian Agricultural University, (Natural Science) 04.

Liao, C.S., Yuan, S.Y., Hung, B.H., Chang, B.V. (2012). Removal of Organic Toxic Chemicals Using the Spent Mushroom Compost of Ganoderma lucidium. Journal of Environmental Monitoring 14: 1983-1988.

Liming X., Xueliang S. (2004). High-yield Celllase Production by Trichoderma reesei ZU-02 On Corn Cob Residue. Bioresource Technology 91: 259-262.

Linyong Z. (2006). Utilization of Spent Mushroom Substrate. Acta Edulis Fungi 13(1): 76-77.

Liu, X., Kokare, C. (2017). Microbial Enzymes of Use in Industry, Biotechnology of Microbial Enzymes Production. Biocatalysis and Industrial Applications 267-298.

Maciel, M.J.M., Silva, A.C., Ribeiro, H.C.T. (2010). Industrial and Biotechnological Applications of Ligninolytic Enzymes of the Basidiomycota: A Review. Electronic Journal Biotechnology 13 (6).

Maher M.J., Lenehan J.J., Staunton W.P. (1993). Spent Mushroom Compost Options for Use, Teagasc Agriculture and Food Development Authority, Kinsealy Research Centre.

Maher, M.J. (1988). Spent Mushroom Compost as An Organic Manure and Potting Compost Component. In W. Bidlingmaier and P. L' Hermite (eds.) Compost processes in waste management, 71-82.

Mandal A. (2015). Review on Microbial Xylanases and Their Applications. International Journal Life Science 4: 178-87.

Martirani, L., Giardina, P., Marzullo, L., Sannia, G. (1996). Reduction of Phenol Content and Toxicity in Olive Oil Mill Waste Waters with the Ligniolytic Fungus Pleurotus ostreatus. Water Research, 30(8):1914-1918.

Mathews, S.L., Smithson, C.E. (2016). Grunden A.M. Purification and Characterization of a Recombinant Laccase Like Multi-copper Oxidase from Paenibacillus glucanolyticus SLM1. Journal Application of Microbiology 121: 13351345.

Michelin, M., Maria de Lourdes T.M., Polizeli Denise, S., Ruzene Daniel, P., Silva José, A.T. (2014). Application of Lignocelulosic Residues in the Production of Cellulase and Hemicellulases from Fungi. Fungal Enzymes, Taylor and Francis Group, LLC, 31-64.

Mitidieri, S., Souza Martinelli, A.H., Schrank, A., Vainstein, M.H. (2006). Enzymatic Detergent Formulation Containing Amylase fromAspergillus niger: A Comparative Study with Commercial Detergent Formulations. Bioresource Technology 97: 1217-1224.

Moreira, L.R.S., Filho, E.X.F. (2016). Insights into the Mechanism of Enzymatic Hydrolysis of Xylan. Applied Microbiology and Biotechnology 100: 5205- 5214.

Mothana, R.A.A., Jansen, R., Julich, W.D., Lindequist, U. (2000). Ganomycins A and B, New Antimicrobial Farnesyl Hydroquinones from the Basidiomycete Ganoderma pfeifferi. Journal National Product 63: 416-418. 
Mukherjee, A.K., Kumar, T.S, Rai, S.K., Roy, J.K. (2010). Statistical Optimization of Bacillus alcalophilus $\alpha$-amylase Immobilization on Iron-oxide Magnetic Nanoparticles. Biotechnology of Bioprocess Engineering 15: 984-992.

Najafi, B., Ardabili, S. F., Shamshirband, S., Chau, K.W. (2019). Spent Mushroom Compost (SMC) as a Source for Biogas Production in Iran. Engineering Applications of Computational Fluid Mechanics 13(1): 967-982.

Osma, J.F., Toca-Herrera, J.L., Rodriguez-Couto, S. (2010). Uses of Laccases in the Food Industry. Enzyme Research, 918761, 1-8.

Palomba, R., Formisano, G., Arrichiello, A., Auriemma, G., Sarubbi, F. (2017). Development of a Laboratory Technique for the Evaluation of Protease Enzymes Activity in Goat and Sheep Milk. Food Chemistry 221: 1637-1641.

Park, S.H., Na, Y., Kim, J., Kang, S.D., Park, K.H. (2018). Properties and Applications of Starch Modifying Enzymes for Use in the Baking Industry. Food Science and Biotechnology 27: 299-312.

Phan, C.W., Sabaratnam, V. (2012). Potential Uses of Spent Mushroom Substrate and Its Associated Lignocellulosic Enzymes. Applied Microbiology and Biotechnology 96(4): 863-873.

Pouliot, A. (2018). The Allure of Fungi. CSIRO Publishing, Clayton South, VIC, Australia

Prakash, O., Jaiswal, N. (2010). a -Amylase: An Ideal Representative of Thermostable Enzymes. Applied Biochemistry and Biotechnology 160: 2401-2414.

Pundir, C.S. (2015). Enzyme Nanoparticles Preparation, Characterisation, Properties and Applications, Micro-Nano Technologies Series, ELSEVIER.

Raveendran S., Parameswaran, B., Ummalyma, S.B, Abraham, A., Mathew, A.K., Madhavan, A., Pandey, S.R.A. (2018). Applications of Microbial Enzymes in Food Industry. Food Technology and Biotechnology 56(1): 16-36.

Rinker, D. L. (2017). Spent Mushroom Substrate Uses, Edible and Medicinal Mushrooms. Technology and Applications, First Edition, Edited by Diego Cunha Zied and Arturo Pardo-Giménez, 427-453.

Russell, M., Basheer, P.A.M., Rao, J.R. (2005). Potential Use of Spent Mushroom Compost Ash as An Activator for Pulverised Fuel Ash. Construction and Building Materials 19: 698-702.

Saini, R., Saini, H. S., Dahiya, A. (2017). Amylases: Characteristics and Industrial Applications. Journal of Pharmacognosy and Phytochemistry 6(4): 1865-1871.

Salinas, V.A., De La Rosa M.J., Sena S.S.O., Chuck H.C. (2015). Yield and Textural Character Istics of Panela Cheeses Hroduced with Dairy- Vegetable Trotein (Soybean or Peanut) Blends Supplemented with Transglutaminase. Journal of Food Science 80 (12): 2950-2956.

Santini, A., Tenore, G.C., Novellino, E. (2017). Nutraceuticals: A Paradigm of Proactive Medicine. European Journal of Pharmaceutical Sciences 96: 53-61.

Satya, J.E., Swasti, D. (2019). Evolutionary Trends in Industrial Production of $\alpha$-amylase. Recent Patents on Biotechnology 13(1): 4-18(15).

Saxena, A., Chauhan, P.S. (2016). Role of Various Enzymes in einking of Paper: A Review. Critical Reviews Biotechnology 15: 1-15.
Shah, A., Patel, H., Narra, M. (2017). Bioproduction of Fungal Cellulases and Hemicellulases Through Solid State Fermentation. Fungal Metabolites 349-393.

Shenggang, X. (2005). Test of Soil Amendment of Orange Garden with Spent Mushroom Substrate. Edible Fungi $6: 48$.

Shuman, L.M. (1998). Effect of Organic Waste Amendments on Cadmium and Lead in Soil Fractions of Two Soils. Communications in Soil Science and Plant Analysis 29(19-20): 2939-2952.

Silva, T.M. (2014). Fungal Amylases, Applications and Functional Properties, CRC Press Group ISBN:9780429074202

Singh, D., Gupta N. (2020). Microbial Laccase: A Robust Enzyme and Its Industrial Applications. Biologia 75: 11831193.

Singh, D., Sharma, K.K., Jacob, S., Gakhar, S.K. (2014). Molecular Docking of Laccase Trotein from Bacillus safensis DSKK5 Isolated from Earthworm Gut: A Novel Method to Study Dye Decolorization Potential. Water Air Soil Pollution 225: 2175, 1-12.

Soccol, C.R., Scopel, E., Alberto, L., Letti, J., Karp, S.G., Woiciechowski, A.L., Vandenberghe, D.S. (2017). Recent Devel Opments and Innovations in Solid State Fermentation. Biotechnology Research Innovation 1: 52-71.

Sondhi, S., Sharma, P., George, N., Chauhan, P.S., Puri, N., Gupta, N. (2015). An Extracellular Thermo-Alkali-Stable Laccase from Bacillus tequilensis SN4, with a Potential to Biobleach Softwood Pul,. 3 Biotechnology 5: 175-185.

Songlin, Z. (2002). Production of Biogas with SMC. Edible Fungi $01: 6$

Spiteller, P. (2008). Chemical Defense Strategies of Higher Fungi. Chemistry Europe Journal 14: 9100-9110.

Sulistiany, H., Sudirman, L.I., Dharmaputra, O.S. (2016). Production of Fruiting Body and Antioxidant Activity of Wild Pleurotus. Journal of Bioscience 23: 191-195.

Sundarram, A., Murthy T. P. K. (2014). a-Amylase Production and Applications: A Review. Journal of Applied and Environmental Microbiology 2(4): 166-175.

Synytsya, A., Mickova, K., Synytsya, A., Jablonsky, I., Spevacek, J., Erban, V., Kovarikova, E., Copikova, J. (2009). Glucans from Fruit Bodies of Cultivates Mushrooms Pleurotus ostreatus and Pleurotus eryngii Structure and Potential Prebiotic Activity. Carbohydrate Polymers 76: 548-556.

Tajbakhsh, J., Abdoli, M.A., Mohammadi, G.E., Alahdadi, I., Malakouti, M.J. (2008). Recycling of Spent Mushroom Compost Using Earthworms Eisenia foetida and Eisenia andrei. Environmentalist 28: 476-482.

Tajkarimi, M., Ibrahim, S., Cliver, D. (2010). Antimicrobial Herb and Spice Compounds in Food. Food Control 21(9): 11991218.

Tan, Y.H., Wahab, M.N. (1997). Extracellular Enzyme Production During Anamorphic Growth in the Edible Mushroom Pleurotus sajor-caju. World Journal of Microbiology and Biotechnology 13: 613-617.

Tumwasorn, S., Chinoros, C., Easpiakdumrong, P., Pattanasettakul, W. (1980). Effects of Different Rice Straws and Dilution Rates of Manures on Biogas Production. Mushroom Newsletter for the Tropics 1(2): 6-10. 
Urbaniec, K., Bakker, R.R. (2015). Biomass Residues as Raw Material for Dark Hydrogen Fermentation A Review. International Journal of Hydrogen Energy 40: 3648-3658.

Velioglu, Z., Ozturk, U.R. (2015). Biosurfactant Production by Pleurotus ostreatus in Submerged and Solid-state Fermentation Systems. Turkish Journal Biology 39: 160-166.

Vigneshwaran, N., Kathe, A.A., Varadarajan, P.V., Nachane, R.P., Balasubramanya, R.H., (2007). Silver- protein (coreshell) Nanoparticle Production Using Spent Mushroom Substrate. Langmuir 23: 7113-7117.

Vrsanska, M., Buresova, A., Damborsky, P., Adam, V. (2015). Influence of Different Inducers on Ligninolytic Enzyme Activities. Journal of Metallomics and Nanotechnologies 3: 64-70.

Wang, T.N., Zhao, M. (2016). A Simple trategy for Extracellular Production of CotA Laccase in Escherichia coli and Becolorization of Simulated Textile Effluent by Recombinant Laccase. Applied Microbiology and Biotechnology 101(2): 685-696.

Wolff, E.R.S., Wisbeck, E., Silveira, M.L.L., Gern, R.M.M., Pinho, M.S.L., Furlan, S.A. (2008). Antimicrobial and Antineoplasic Activity of Pleurotus ostreatus. Applied Biochemistry Biotechnology, 151: 402-412.
Wu, S., Lan, Y., Huang, D., Peng, Y., Huang, Z., Xu, L. (2014). Use of Spent Mushroom Substrate for Production of Bacillus thuringiensis by Solid State Fermentation. Journal of Economic Entomology 107(1): 137-143.

Wu, S., Lan, Y., Wu, Z., Peng, Y., Chen, S., Huang, Z. (2013). Pretreatment of Spent Mushroom Substrate for Enhancing the Conversion of Fermentable Sugar. Bioresource Technology 148: 596-600.

Wuest, P. J., Fahy, H.K. (1991). Spent Mushroom Compost, Traits and Uses. Mushroom News, 39(12): 9-15.

Yamaç, M., Pekşen, A. (2016). Atık Mantar Kompostu/Substratının Kullanım Alanları-2: Lignoselülozik Enzim Ekstraksiyonu (Using Areas of Spent Mushroom Compost/Substrate-2: Extraction of Lignocellulosic Enzymes). Mantar Dergisi, 7(1): 66-77.

Zahid, S., Udenigwe, C.C., Ata, A., Eze, M.O., Segstro, E.P., Holloway, P. (2006). New Bioactive Natural Products from Coprinus micaceus. Natural Product Research, 20: 12831289.

Zarei, M., Forghani, B., Ebrahimpour, A., Abdul-Hamid, A., Anwar, F., Saari, N. (2015). In Vitro and in Vivo Antihy-pertensive Activity of Palm Kernel Cake Protein Hydrolysates: Sequencing and Characterization of Potent Bioactive Peptides. Industrial Crops and Products 76: 112-120.

Zhengfeng, L. (1997). Edible Fungus Residue Can be Used to Produce Plant Hormones. Edible Fungi of China 16(4): 19. 